\title{
RESPIRATORY MUSCLE STRENGTH OF BRAZILIAN ADOLESCENTS: OBTAINED AND PREDICTED VALUES
}

\author{
Priscilla Rique Furtado', Tania Fernandes Campos², Raquel Emanuele de França Mendes ${ }^{1}$, \\ Diana Amélia de Freitas ${ }^{1}$, Gabriela Suéllen da Silva Chaves ${ }^{1}$, \\ Thalita Medeiros Fernandes de Macêdo', Karla Morganna Pereira Pinto de Mendonça²
}

\begin{abstract}
Objectives: To compare the obtained values for maximal respiratory pressures of a sample of Brazilian adolescents with the values predicted by Wilson et al. and Domènech-Clar et al. Methods: 156 adolescents (84 boys) aged between 12 and 17 years were assessed. Maximal respiratory pressures were assessed by a digital manometer with the adolescents in the seated position and wearing a nose clip. Maximal inspiratory and expiratory pressures were performed from residual volume and total lung capacity, respectively. Comparison of the values of maximal respiratory pressures obtained in this study with those predicted by the equations proposed by Wilson et al. and Domenèch-Clar et al., was performed by the paired Student's test. To verify the association between these values, the Pearson's correlation test was used. Results: Mean maximal inspiratory pressure was 74,66 $\pm 22,95 \mathrm{~cm} \mathrm{H}_{2} \mathrm{O}$ and 103,52 $\pm 25,67 \mathrm{~cm} \mathrm{H}_{2} \mathrm{O}$ for girls and

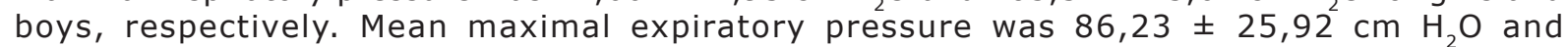
$120,08 \pm 27,37 \mathrm{~cm} \mathrm{H} 2 \mathrm{O}$ for girls and boys, respectively. The values obtained by this study did not differ and also did not significantly correlate with those predicted by the equations proposed by Wilson et al., e Domènech-Claret al. Conclusions: The equations proposed by Wilson et al. and Domènech-Clar et al. were not successful in predicting the values for maximal respiratory pressures in the population studied, indicating the necessity of using in clinical practice reference values from a healthy population of the same ethnicity.
\end{abstract}

Key words: muscle strength, respiratory muscles, evaluation, reference values, adolescent.

\section{INTRODUCTION}

The measurement of maximal static respiratory pressures (MRP) at the mouth provides subsidies to direct the preoperative and postoperative therapeutic goals ${ }^{1}$, assess the response to respiratory muscle training and allows early muscle weakness identification in various pathological conditions ${ }^{2}$. The measurement of maximal expiratory and inspiratory pressures (MEP and MIP respectively) are crucial to the adequate asses'sment of pulmonary function, and can be performed in healthy individuals of different ages, or in individuals with disorders of different origins 3.4 .

Several studies have been developed in order to provide reference values for MRP or formulate equations able to predict these values ${ }^{5,6}$. Thus, variables such as: age, sex, height, weight, physical activity level and ethnicity were considered, which motivated further researches with different samples in order to compare values found with predicted ones in previous studies, or to present new predicted equations ${ }^{2,7-11}$.

In 1984, Smith et al. ${ }^{7}$ highlighted the lack of studies with MR Pin adolescents and evaluated 112 individuals of different ages, among them 76 adolescents of both sexes, publishing the data as normal values. In the same year, Wilson et al. ${ }^{6}$ studied 235 subjects between 7 and 17 years, of both sexes, and provided predicted equations for MIP and MEP considering the independent variables: weight and age. Later, Szeinberg et al., in $1987^{12}$, published reference values from a sample of 270 subjects aged between 8 and 40 years (243 children and adolescents). In 2003, Domènech-Clar et al. ${ }^{8}$ provided predicted

1 Programa de Pós-Graduação em Fisioterapia, Universidade Federal do Rio Grande do Norte - UFRN. Avenida Senador Salgado Filho, 3000, Departamento de Fisioterapia, Campus Universitário, Lagoa Nova, Natal, RN, Brasil.

2 Professora Associada, Programa de Pós-Graduação em Fisioterapia, Departamento de Fisioterapia - UFRN. Avenida Senador Salgado Filho, 3000, Departamento de Fisioterapia, Campus Universitário, Lagoa Nova, Natal, RN, Brasil.

Instituição: Departamento de Fisioterapia da Universidade Federal do Rio Grande do Norte (UFRN), Natal, Rio Grande do Norte, Brasil.

Fonte financiadora: projeto executado com recursos próprios. O presente estudo é parte de uma dissertação de mestrado denominada "Equações preditivas para as pressões respiratórias estáticas máximas de adolescentes brasileiros", defendida em Natal na Universidade Federal do Rio Grande do Norte (UFRN) - Programa de Pós-Graduação em Fisioterapia, em 2012. Corresponding author: kmorganna@ufrnet.br

Suggested citation: Furtado PR, et al. Respiratory muscle strength of brazilian adolescents: obtained and predicted values, Journal of Human Growth and Development, 24(2):168-174

Manuscript submitted Aug 01 2013, accepted for publication Dec 282013. 
equations from the assessment of 392 Spanish children and adolescents between 8 and 17 years. Similarly to the study of Wilson et al. ${ }^{6}$, the equations proposed by Domènech-Claret al. ${ }^{8}$ considered the same variables, however adding the variable height. All mentioned studies have performed the comparison between obtained and predicted values, finding differences between results.

Studies conducted in Brazil have shown that it is necessary to evaluate different populations and provide different parameters for them, once there may be differences between the characteristics of these individuals, in distinct regions of the same country ${ }^{9,10}$ and even in the same region?.

To the best of our knowledge, the predicted equations and parameters of normality offered by Wilson et al. ${ }^{6}$ and Domènech-Clar et al. ${ }^{8}$ have been the most widely used as reference in the evaluation of respiratory muscle strength of adolescents from different nationalities. However, comparative studies using a sample of Brazilian adolescents were not found.

Thus, the aim of this study is to compare the values found with those predicted by Wilson et al. ${ }^{6}$ and Domènech-Clar et al. ${ }^{8}$ and to verify if the predicted values are suitable to be used in a population of Brazilian adolescents.

\section{METHODS}

This is a cross-sectional study conducted in accordance with the Declaration of Helsinki and approved by the Research Ethics Committee of Federal University of Rio Grande do Norte (UFRN), protocol number 278/2009. Sample calculation was conducted according to the formula to estimate the mean supplied by the Laboratory of Epidemiology and Statistics ${ }^{13}$ resulting in 14 boys and 12 girls for each age group assessed.

The subject's selection was made from a list of public and private schools in the city of Natal provided by the $1^{\text {st }}$ Regional Education Directorate (DIRED). By a previous contact, a letter explaining the study was delivered to parents and/or guardians, accompanied by an informed consent form and a respiratory questionnaire, composed of nine questions regarding respiratory symptoms, validated for diagnosis of respiratory diseases. This is recommended by The American Thoracic Society and Division of Lung Diseases ${ }^{14}$. Inclusion criteria were: aged between 12 and 17 years ${ }^{15}$, be eutrophic ${ }^{16}$; do not have chronic lung, neuromuscular or cardiovascular disease, as well as reporting the use of medications that might interfere in the performance during assessments ${ }^{17}$; neurological damage or inability to understand the guidelines for using the manovacuometer ${ }^{3,17}$; recent upper airway, chest or abdominal trauma; acute middle ear infection; abdominal hernia; glaucoma or retinal detachment $^{3}$; fever in the three previous weeks ${ }^{3}$ and flu and/or cold in the week prior to the procedure; or have past history of smoking; thoracic deformity 3 ; or a score of 7 or higher on the standardized questionnaire of the American Thoracic Society and Division of Lung Diseases ATSDLD-78-C14.

Individuals excluded were those unable to perform the necessary procedures and those who declined to participate; exhibited acute respiratory tract disease during the collection period; missed class during the evaluation period at their school; displayed values lower than $80 \%$ of those predicted for Peak Expiratory Flow (PEF), Forced Vital Capacity (FVC), Forced Expiratory Volume (FEV), Forced Expiratory Volume in the first second $\left(\mathrm{FEV}_{1}\right.$ ) and the $\mathrm{FEV}_{1} / \mathrm{FVC}$ ratio, as well as values less than $70 \%$ of those predicted for mean Forced Expiratory Flow between 25 and $75 \%$ of the FVC curve $\left(\mathrm{FEF}_{25} 75 \%\right)$ - in accordance with ATS ${ }^{18}$ criteria. The measures proposed by Mallozi ${ }^{19}$ were used as reference values.

On the scheduled day, each adolescent underwent anthropometric assessment. The Anthro Plus software from the World Health Organization (WHO) automatically provided the nutritional status.

Heart rate and peripheral oxygen saturation were verified with the purpose of monitoring the adolescent for possible interruption of the evaluation before complications. The instruments used were a Visomat $($ Handy IV digital sphygmomanometer (UEBE Medical Gmb H, Germany) and an Onyx $\circledR$ II 9550 Pulse Oximeter (Nonin Medical, PlymouthMN, United States of America).

In order to avoid air escape, all measurements were performed with the adolescent using a nose clip and instructed to properly adjust their lips around the mouthpiece ${ }^{8}$. Because this was an effort-dependent test, the examiner provided verbal encouragement during assessments. The adolescents remained seated with their heads in a neutral position.

\section{Spirometry}

Spirometry was performed using a hand held One Flow FVC digital spirometer (Clemente Clark International - England)

Initially, the adolescents performed three respiratory cycles at tidal volume, and then they were instructed to perform one maximum inspiration (indicated by a predetermined gesture), close their mouth firmly around the mouthpiece and, following a minimum pause, make a vigorous maximum expiration. The maneuvers produced flow - volume and time-volume curves that, for its use in the interpretation, should be in accordance with the acceptability and reproducibility criteria recommended by the American Thoracic Society ${ }^{20}$ : realization of a maximum inspiration before the beginning of the test; a minimum pause (1-2 seconds); expiration with maximum effort; satisfactory test duration (6 seconds); and the lack of artifacts.

A minimum of three and maximum of eight maneuvers were executed. Of these, three were acceptable, and the best two did not exhibit a maximum difference of $0.150 \mathrm{~L}$ between them, 
with the better of the two tests chosen. A oneminute rest was permitted between each maneuver ${ }^{18}$.

\section{Manovacuometry}

After 10 minutes of rest, the same examiner conducted the assessment of maximal respiratory pressures. MRP were assessed using an MVD 300 digital manometer (Globalmed $\AA$, Porto Alegre RS, Brazil). A disposable biological filter (Vida Tecnologia Biomédica, São Paulo - SP, Brazil) was attached to a Rescal adaptor which connects the system with the ambient air. This was coupled to a rigid and flattened plastic mouthpiece (Globalmed $®$, Porto Alegre - RS, Brazil) with a 2$\mathrm{mm}$ wide hole on its upper surface.

The evaluation was performed with the manometer connected to a laptop (Compac Presario CQ50-113BR). The computer software provided the subject with visual feedback, and auditory feedback was given by the examiner. MRP measurement was performed in accordance with the method proposed by Souza ${ }^{3}$.

Initially, adolescents randomly selected the first MRP to be assessed. To assess MIP the adolescents were instructed to perform three respiratory cycles at tidal volume and then perform a maximum expiratory effort up to approximately the residual volume (RV). The adolescents indicated the maximum effort by a predetermined gesture. At that moment they were instructed to perform a maximal inspiration (until approximate total lung capacity - TLC). Instructions were similar for MEP assessment, except participants first performed a maximal inspiration and then maximal expiration following occlusion of the orifice. During this measurement the examiner manually supported the adolescents'cheeks ${ }^{21}$.

A maximum of nine maneuvers were performed for each MRP assessment ${ }^{8}$. Of these, at least three had to be acceptable (without leaking, with a duration of at least $2 \mathrm{~s}$ and sustained for 1s), from which a minimum of two were required to be reproducible (with a difference between them of no more than $10 \%$ of the highest value). The better of these two values was selected ${ }^{8}$. However, the last measurement could not be the highest, and another measurement was taken when this occurred. A one-minute rest was permitted between each maneuver, with five minutes allowed between MIP and MEP assessments.

The equipment used in this investigation only directly supplies peak pressure values (the highest value during the maneuver) ${ }^{22}$. As such, sustained pressure values were determined by examining the pressure versus time curve provided by the manometer software.

\section{Analysis of data}

Data were analyzed using SPSS statistics software version 17.0 , with a significance level of $5 \%$. Data normality was verified by the Kolmogorov-Smirnov test. Descriptive statistics are expressed as mean and standard deviation.
One-way analysis of variance (ANOVA), followed by the Bonferroni post hoc test, was used to determine whether there was a significant difference in MRP according to age and sex. Non-paired Student's t-test was applied to verify inter-gender differences. Unpaired Student's t-test was used to establish the existence of differences between the mean MIP and MEP values obtained in the present study and those from the equations proposed by Wilson et $a l .{ }^{6}$ and Domènech-Claret al. ${ }^{8}$ The Pearson's correlation test was performed to verify the association between those values. Levene's test was performed to assess the homogeneity of variances (homoscedasticity). The lower limit of normal (LLN) was calculated by subtracting a value two times greater than the standard deviation of the measurements from mean MRP ${ }^{3}$.

\section{RESULTS}

244 questionnaires were returned, 28 teenagers were not included in the sample for non-compliance with one of the inclusion criteria. Among the 216 adolescents selected, 60 were excluded (3 refused to take part, 39 were not classified as eutrophic, 13 did not meet criteria established by spirometry and 5 were unable to perform acceptable and reproducible manovacuometer maneuvers among the maximum number of nine measurements), resulting in a total sample of 156 subjects, 84 boys and 72 girls. Table 1 describes the anthropometric variables, expressed as mean and standard deviation.

MIP and MEP values had normal distribution with a significant level of $p=0,49$ and $p=0,55$, respectively. ANOVA indicated no significant difference between respiratory muscle strength and age (12-17 years) with a $P$ value of 0,18 for MIP and 0,749 for MEP.

Table 2 describes the means obtained for maximal respiratory pressures in boys and girls. This table also shows the lower limits of normal of the adolescents assessed.

Table 3 shows the inexistence of significant difference for comparison of maximal respiratory pressure values found with the ones predicted by the equations proposed by Wilson et al. ${ }^{6}$ and Domènech-Clar et al. ${ }^{8}$

The dispersion graphs of MRP values found and those predicted in equations proposed by Wilson et $a l .{ }^{6}$ and Domènech-Clar et al. ${ }^{8}$ are shown in figures 1 and 2, respectively. Obtained values of MIP and MEP in both sexes had low coefficients and did not present significant correlation with the values predicted by Wilson et al. ${ }^{6}$ and Domènech-Claret al. ${ }^{8}$

\section{DISCUSSION}

When comparing the values found for maximal respiratory pressures from a sample of 156 healthy Brazilian adolescents with the values 
Table 1: Description of anthropometric variables, expressed as mean and standard deviation, according to age and sex

$\begin{array}{llll}\text { Age (years) } & & \text { Girls }(\mathbf{n}=\mathbf{7 2}) & \text { Boys }(\mathbf{n}=\mathbf{8 4}) \\ 12(\mathrm{n}=12914 \sigma) & \text { Weight }(\mathrm{Kg}) & 46,33 \pm 9,80 & 42,92 \pm 6,12 \\ & \text { Height }(\mathrm{m}) & 1,56 \pm 0,08 & 1,54 \pm 0,08 \\ & \text { BMI }\left(\mathrm{Kg} / \mathrm{m}^{2}\right) & 18,69 \pm 2,57 & 17,92 \pm 2,26 \\ 13(\mathrm{n}=12914 \sigma) & \text { Weight }(\mathrm{Kg}) & 44,75 \pm 6,60 & 54 \pm 6,96 \\ & \text { Height }(\mathrm{m}) & 1,58 \pm 0,05 & 1,66 \pm 0,05 \\ & \text { BMI }\left(\mathrm{Kg} / \mathrm{m}^{2}\right) & 17,72 \pm 2,32 & 19,41 \pm 1,74 \\ 14(\mathrm{n}=12914 \sigma) & \text { Weight }(\mathrm{Kg}) & 1,59 \pm 0,79 & 54,14 \pm 9,72 \\ & \text { Height }(\mathrm{m}) & 19,41 \pm 2,29 & 1,66 \pm 0,08 \\ & \text { BMI }\left(\mathrm{Kg} / \mathrm{m}^{2}\right) & 53,50 \pm 7,45 & 19,50 \pm 1,96 \\ 15(\mathrm{n}=12914 \sigma) & \text { Weight }(\mathrm{Kg}) & 1,62 \pm 0,07 & 1,07 \pm 7,94 \\ & \text { Height }(\mathrm{m}) & 18,46 \pm 6,36 & 18,71 \pm 5,06 \\ 16(\mathrm{n}=12914 \sigma) & \text { BMI }\left(\mathrm{Kg} / \mathrm{m}^{2}\right) & 52,50 \pm 7,11 & 64,14 \pm 8,52 \\ & \text { Weight }(\mathrm{Kg}) & 1,61 \pm 0,05 & 1,74 \pm 0,07 \\ & \text { Height }(\mathrm{m}) & 20,06 \pm 2,70 & 20,95 \pm 1,87 \\ 17(\mathrm{n}=12914 \sigma) & \text { BMI }\left(\mathrm{Kg} / \mathrm{m}^{2}\right) & 54,25 \pm 10,92 & 68,07 \pm 8,68 \\ & \text { Weight }(\mathrm{Kg}) & 1,62 \pm 0,06 & 1,74 \pm 0,07 \\ & \text { Height }(\mathrm{m}) & 20,45 \pm 3,15 & 22,35 \pm 1,94\end{array}$

BMI: body mass index.

$\uparrow:$ Female; $\sigma$ : Male.

Table 2:Comparison of maximal respiratory pressures between boys and girls and lower limits of normal for the adolescents assessed

$\begin{array}{llll}\text { Obtained values } & \text { Girls }(\mathbf{n = 7 2}) & \text { Boys }(\mathbf{n = 8 4}) & \text { P value } \\ \text { MIP }\left(\mathrm{cmH}_{2} \mathrm{O}\right) & 74,66 \pm 22,95 & 103,52 \pm 25,67 & 0,000 \\ \operatorname{MEP}\left(\mathrm{cmH}_{2}\right) & 86,24 \pm 25,92 & 120,08 \pm 27,37 & 0,000 \\ \text { LLN MIP }\left(\mathrm{cmH}_{2} \mathrm{O}\right) & 28,76 & 52,18 & \\ \text { LLN MEP }\left(\mathrm{cmH}_{2} \mathrm{O}\right) & 34,40 & 65,34 & \end{array}$

MIP: maximal inspiratory pressure; MEP: maximal expiratory pressure.

LLN: lower limit of normal. Statistically significant $(p<0.05)$.

Table 3:Comparison of obtained maximal inspiratory and expiratory pressures with those predicted byWilson et al. ${ }^{6}$ andDomènech-Claret $a l .^{8}$

\begin{tabular}{|c|c|c|c|c|c|c|}
\hline MRP & $\mathbf{n}$ & $\begin{array}{l}\text { Obtained } \\
\text { values } \\
\left(\mathrm{cmH}_{2} \mathrm{O}\right)\end{array}$ & $\begin{array}{l}\text { Predicted values by } \\
\text { Wilson et al. } \\
\left(\mathrm{cmH}_{2} \mathrm{O}\right)\end{array}$ & P value & $\begin{array}{c}\text { Predicted values by } \\
\text { Domènech-Claret al. } \\
\left(\mathrm{cmH}_{2} \mathrm{O}\right)\end{array}$ & P value \\
\hline \multicolumn{7}{|l|}{ MIP } \\
\hline Girls & 72 & $74,67 \pm 22,92$ & $68,47 \pm 4,91$ & 0,579 & $91,88 \pm 7,86$ & 0,398 \\
\hline Boys & 84 & $103,52 \pm 25,67$ & $86,95 \pm 8,69$ & 0,583 & $116,00 \pm 13,21$ & 0,709 \\
\hline \multicolumn{7}{|l|}{ MEP } \\
\hline Girls & 72 & $86,24 \pm 25,92$ & $93,50 \pm 8,21$ & 0,963 & $98,67 \pm 9,63$ & 0,980 \\
\hline Boys & 84 & $120,08 \pm 27,37$ & $114,50 \pm 9,37$ & 0,382 & $159,86 \pm 21,01$ & 0,436 \\
\hline
\end{tabular}

MIP: maximal inspiratory pressure; MEP: maximal expiratory pressure. MRP: maximal respiratory pressures. Statisticallysignificant $(p<0.05)$. 

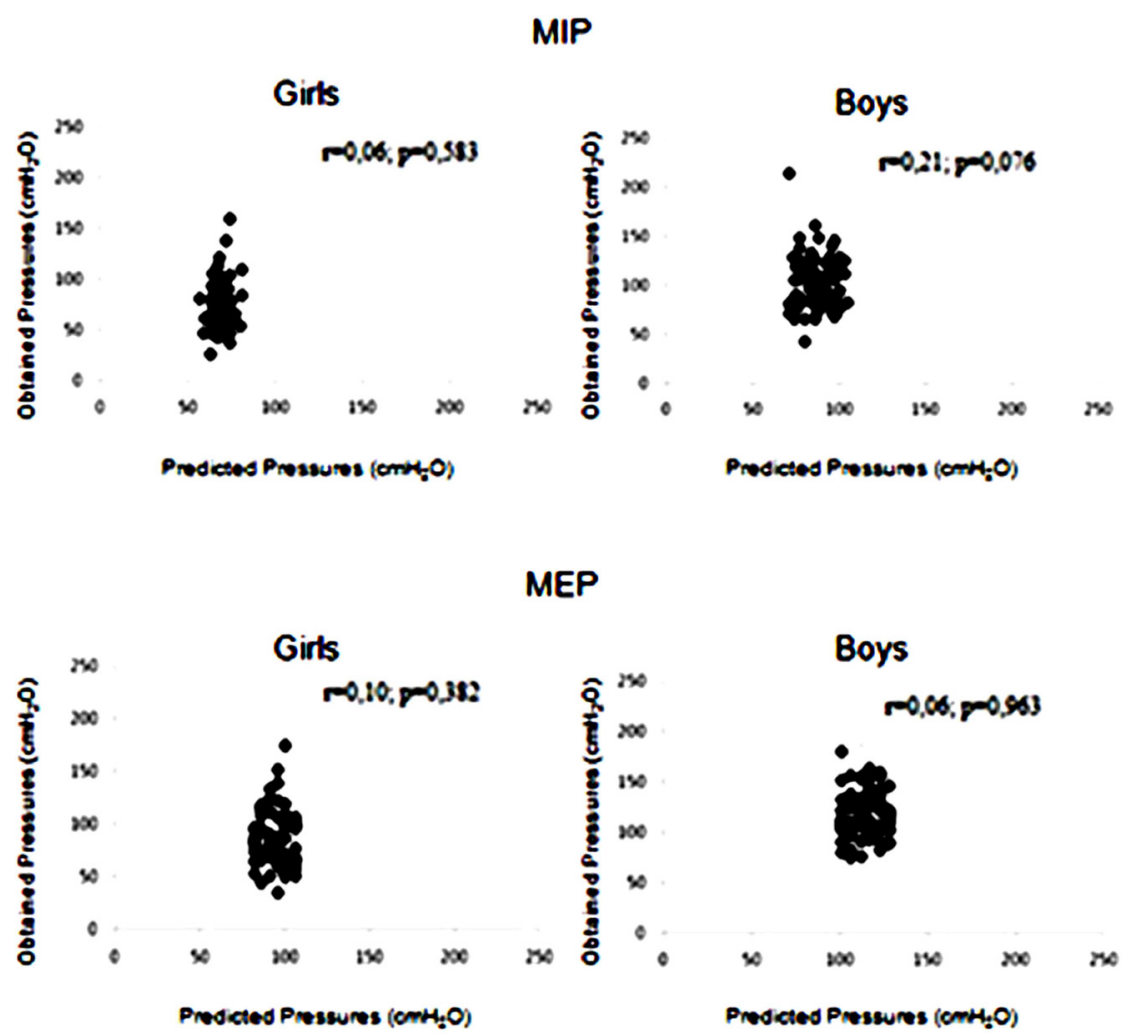

Figure 1: Dispersion diagrams of maximal inspiratory pressures (MIP) and maximal expiratory pressures (MEP) obtained in the present study and the values predicted by equations proposed by Wilson et al. ${ }^{6}$
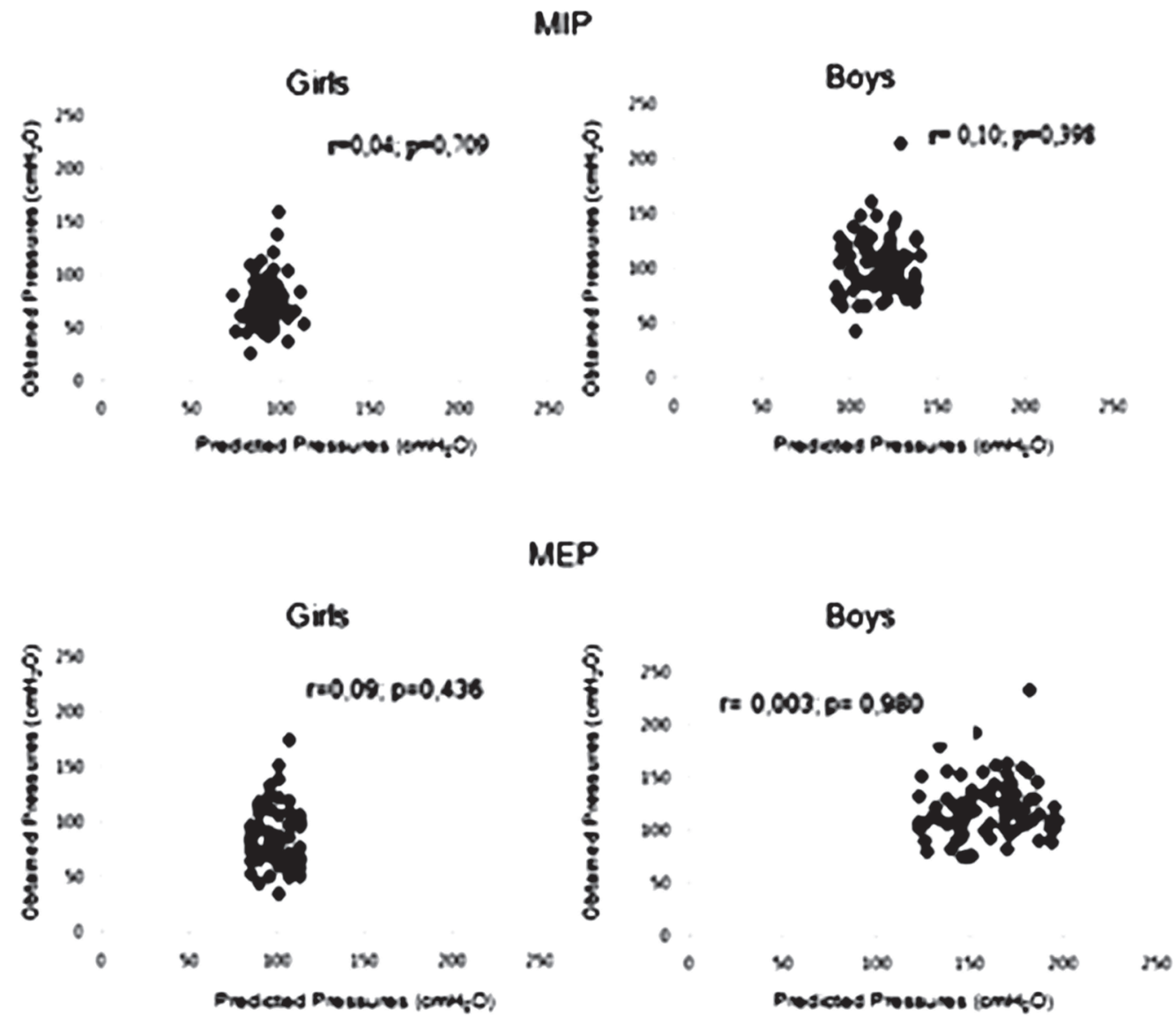

Figura 2: Dispersion diagrams of maximal inspiratory pressures (MIP) and maximal expiratory pressures (MEP) obtained in the present studies and the values predicted by equations proposed by Domènech-Claret al. ${ }^{8}$ 
predicted by Wilson et al. (1984) ${ }^{6}$ and DomenèchClar et al. $(2003)^{8}$ it was verified that the equations proposed by these authors were not able to predict respiratory muscle strength of Brazilian adolescents.

Although the differences are not significant, there was weak correlation without statistical significance between the values found in the current study and the predicted ones by both studies $^{6,8}$. According to Parreira et al. ${ }^{9}$, to assert that there is concordance between found and predicted maximal respiratory pressures values it is necessary that these measures do not show statistical difference and present a significant correlation.

During the last years, several studies have comparatively analyzed maximal respiratory pressures and highlighted the discrepancies observed between found and predicted values in different age groups ${ }^{7,9-11}$. Such fact has been attributed to methodological differences, to the quantity and quality of samples evaluated, to equipments and techniques used, besides geographical, social and anthropometric differences of the individuals ${ }^{9}$.

With regard to technique's aspects, it is argued that the use of a nose clip and a flanged mouthpiece contribute to reduce the risks of air escape and consequently avoid the under estimation of the real values measured for maximal respiratory pressures ${ }^{10}$. This aspect may justify the possible underestimation of the obtained values by the study of Wilson et al. ${ }^{6}$ in which a nose clip has not been used. Another aspect to be considered, is the examiner support of the cheeks during the expiratory efforts which according to Clanton and Diaz ${ }^{21}$ aims to ensure that the pressure exerted by the respiratory muscles is transmitted to the device instead of staying stuck in the oral cavity by distention of the cheeks and air concentration in that area. In the study of Domenèch-Clar et al.8 the adolescents performed MEP with their hands over their cheeks, while in the current study the examiner supported the adolescents' cheeks. Studies with the aim to investigate differences in results regarding this aspect were not found; however it is possible that this methodological factor might interfere in the results.

The results show that the mean values of MRP in boys were significantly higher than those observed in girls. Similar findings have been reported in several studies performed with samples of children 6,12 , adolescents 7,8 , and adults ${ }^{2,6,9,10}$. The most accepted explanation for this difference involves the existence of greater

\section{REFERENCES}

1. Paisani DM, Chiavegato LD, Faresini SM.Volumes, capacidades pulmonares e força muscular respiratória no pós-operatório de gastroplastia. J Bras Pneumol. 2005; 31(2):125-32. doi: 10.1590/S1806-37132 005000200007 amount of lean body mass in boys, which is even greater after puberty ${ }^{8}$, and to the fact that, in general, the males are more physically active ${ }^{23}$. In females, hormonal changes play an important role in puberty and during the menstrual cycle may interfere in MRP measures as it was verified by Silva et al. ${ }^{24}$ These authors commented on the existence of a positive influence of estradiol and progesterone hormones on the respiratory muscle strength in the luteal phase.

Considering the learning effect, a minimum of 3 and a maximum of 9 maneuvers were performed in the current study to achieve 3 acceptable and 2 reproducible maneuvers ${ }^{11}$. Domenèch-Clar et al. ${ }^{8}$ used a similar parameter. However, Wilson et al. ${ }^{6}$ did not establish a maximum limit, it was only determined the performance of at least 3 maneuvers. In 1997, a study conducted by Wen et al. ${ }^{25}$ stated that a larger number of maneuvers could determine more effectively there spiratory muscle weakness. In opposition to this perspective, Smyth et al. ${ }^{7}$ stated that in clinical practice the performance of successive repetitions of these maneuvers can be impractical in the assessment of patients. In addition, a recent study when comparing the number of maximal respiratory pressures maneuvers performed, observed that there was no difference in the perceived exertion rate of children who performed up to five or more than five maneuvers ${ }^{26}$.

One important difference to be considered among maximal respiratory pressures studies consists of the ethnic differences. Several authors emphasized the differences in MRP values of individuals from different nationalities, and even in the same region of a country ${ }^{5,9-11}$. Nevertheless, references of studies that compared MRP values obtained in a sample of Brazilian adolescents with the predicted values by previous studies from other nationalities were not found. This theme was only previously studied in populations of children and adults ${ }^{27,28}$. Such fact highlights the importance of this study to contribute to the advancement of investigation of MRP values that can be used as reference.

A limiting factor in the present study was the absence of hormonal evaluation which would allow a better understanding of the puberty changes influences in respiratory muscle strength during adolescence. Another aspect that may limit the interpretation of the findings of the current study is the divergence observed between the age groups evaluated in previous studies, as well as the lack of information about the characteristics of samples evaluated which would allow more appropriate comparisons.

2. Black LF, Hyatt RE. Maximal respiratory pressures: normal values and relationship to age and sex. Am Rev Respir Dis. 1969; 99(5): 696-702.

3. Souza RB. Pressões respiratórias estáticas máximas. J Pneumol. 2002; 28 (Suppl 3): S155-65. 
4. Oliveira KM, Macêdo TM, Borja RO, Nascimento RA, Medeiros Filho WC, Campos TF et al. Força muscular respiratória e mobilidade torácica em crianças e adolescentes com leucemia aguda e escolares saudáveis. Rev Bras Cancerol. 2011;57(4):511-7.

5. Johan A, Chan CC, Chia HP, Chan OY, Wang YT. Maximal respiratory pressures in adult Chinese, Malays and Indians. Eur Respir J. 1997; 10(12): 2825-8. doi: 10.1183/ 09031936.97 .1012282

6. Wilson SH, Cooke NT, Edwards RH, Spiro SG. Predicted normal values for maximal respiratory pressures in caucasian adults and children. Thorax. 1984;39(7):535-8. doi: 10.1136/thx.39.7.535

7. Smyth RJ, Chapman KR, Rebuck AS. Maximal inspiratory and expiratory pressures in adolescents. Normal values. Chest. 1984; 86(4): 568-72. doi $10.1378 /$ chest.86.4.568

8. Domènech-Clar R, López-Andreu JA, CompteTorrero $L$, de Diego-Damiá A, Macián-Gisbert $\mathrm{V}$, Perpiñá-Tordera $\mathrm{M}$, et al. Maximal static respiratory pressures in children and adolescents. Pediatr Pulmonol. 2003; 35(2): 126-32. doi: 10.1002/ppul.10217

9. Parreira VF, França DC, Zampa CC, Fonseca MM, Tomich GM, Britto RR. Pressões respiratórias máximas: valores encontrados e preditos em indivíduos saudáveis. Rev Bras Fisioter. 2007;11(5):361-8. doi: 10.1590/ S1413-35552007000500006

10. Costa D, Gonçalves HA, Lima LP, Ike D, Cancelliero KM, Montebelo MIL. Novos valores de referência para pressões respiratórias máximas na população brasileira. J Bras Pneumol. 2010;36(3):306-12. doi: 10.1590/ S1806-37132010000300007

11. Freitas DA, Borja RO, Ferreira GM, Nogueira PA, Mendonça KM. Predictive equations and normal values for maximal respiratory pressures in childhood and adolescence. Rev Paul Pediatr. 2011;29(4):656-62. doi: $10.1590 /$ S0103-05822011000400028

12. Szeinberg A, Marcotte JE, Roizin H, Mindorff C, England S, Tabachnik et al. Normal values of maximal inspiratory and expiratory pressures with a portable apparatus in children, adolescents, and young adults. Pediatr Pulmonol. 1987;3(4):255-8.

13. Laboratório de Epidemiologia e Estatística [homepage on the Internet]. Tamanho de amostra para pesquisa em ciências da saúde [cited 2012 Feb 2]. Available from: http:// www.lee.dante.br/pesquisa/amostragem/ amostra.html

14. Esteves A SD, Ferraz M. Adaptation and validity of the ATS-DLD-78-C questionnaire for asthma diagnosis in children under 13 years of age. BrazPed News. 1999;1: 3-5.

15. Brasil - Presidência da República. Lei. $n^{\circ}$ 8.069, de 13 de Julho de 1990. Dispõe sobre - Estatuto da criança e do adolescente. Brasília: Diário Oficial da República, 1990.

16. Brasil - Ministério da Saúde. Secretaria de atenção à saúde - departamento de aten- ção básica - SISVAN [Internet]. Incorporação da curva de crescimento da Organização Mundial da Saúde de 2006 e 2007 nos SISVAN [cited 2012 Jun 2]. Available from: http://189.28.128.100/nutricao/docs/geral/ curvas_oms_2006_2007.pdf

17. Harik-Khan RI, Wise RA, Fozard JL. Determinants of maximal inspiratory pressure. The Baltimore longitudinal study of aging. Am J Respir Crit Care Med. 1998;158(5):1459-64.

18. Rodrigues JC, Cardieri JM, Bussamra MH, Nakaie CM, Almeida MB, Silva Filho LV, et al. Provas de função pulmonar em crianças e adolescentes. J Pneumol.2002;28 (Suppl 3):S207-21.

19. Mallozi MC. Valores de referência para espirometria em crianças e adolescentes, calculados a partir de uma amostra da cidade de São Paulo [Dissertação]. São Paulo: Escola Paulista de Medicina, 1995.

20. Miller MR, Hankinson J, Brusasco V, Burgos F, Casaburi R, Coates $A$, et al. Standardisation of spirometry. Eur Respir J. 2005;26(2):31938. doi: 10.1183/09031936.05.00034805

21. Clanton TL, Diaz PT. Clinical assessment of the respiratory muscles. Phys Ther. $1995 ; 75(11): 983-95$.

22. Montemezzo D, Vieira DS, Tierra-Criollo CJ, Britto RR, Veloso M, Parreira VF. Influence of four interfaces in the assessment of maximal respiratoy pressures. Respir Care. 2012; 57(3): 392-8. doi: 10.4187/respcare.01078

23. Jenovesi JF, Bracco MM, Colugnati FA, Taddei JA. Evaluation in the physical activity level of schoolchildren observed during 1 year. Rev Bras Cineantropom Desempenho Humano. 2004; 12(1): 19-24.

24. Silva SB, Viana ES, Sousa MB. Changes in peak expiratory flow and respiratory strength during the menstrual cycle. Respir Physiol Neurobiol. 2006;150(2,3):211-9. doi: $10.1016 /$ j.resp.2005.03.001

25. Wen AS, Woo MS, Keens TG. How many maneuvers are required to measure maximal inspiratory pressure accurately. Chest. 1997; 111(3): 802-7. doi:10.1378/chest.111.3.802

26. Oliveira JS, Campos TS, Borja RO, Silva ROE, Freitas DA, Oliveira LC, Mendonça KMPP. Analysis of the rate of perceived exertion in the assessment of maximal respiratory pressures in children and adolescents. J Hum Growth Developm. 2012;22(3):314-20.

27. Leal AH, Hamasaki TA, Jamami M, Di Lorenzo VA, Pessoa BV. Comparação entre valores de força muscular respiratória medidos e previstos por diferentes equações. Fisioter Pesqui 2007; 14:25-30.

28. Nascimento RA, Campos TF, Melo JBC, Borja RO, Freitas DA, Mendonça KMPP. Obtained and predicted values for maximal respiratory pressures of Brazilian children. J Hum Growth Dev. 2012;22(1):166-72. 